Global Co-Operation in the New Millennium

The 9th European Conference on Information Systems

Bled, Slovenia, June 27-29, 2001

\title{
THE REQUIREMENTS OF METHODOLOGIES FOR DEVELOPING WEB APPLICATIONS
}

\author{
Craig Standing \\ School of Management Information Systems; Edith Cowan University, Western Australia \\ Tel.: 61894005545 , Fax: 61894005633 \\ c.standing@ecu.edu.au
}

\begin{abstract}
The Internet has had a significant impact on the process of developing information systems. However, there has been little research that has examined specifically the role of development methodologies in this new era. Although there are many new forces driving systems development many other issues are extensions of problems that have been there for some years. This paper identifies the main requirements of methodologies for developing Web applications. To achieve this objective a methodology is proposed which attempts to address a number of issues identified within the literature. The Internet Commerce Development Methodology (ICDM) considers evolutionary development of systems, provides a business and strategic focus and includes a management structure in addition to covering the engineering aspects of Web application development. The methodology is compared with several other Web development methodologies. ICDM differs in that it provides a framework for developing an e-business strategy, incorporates a management structure, procedures for customer involvement and provides guidelines on developing a conducive organisational culture. Evaluation of the method highlighted that practitioners would ideally like methodologies to be relevant to their industry and provide detailed guidelines on changing organisational culture.
\end{abstract}

\section{INTRODUCTION}

The popular assumption is that processes, methods and techniques used for applications development have changed radically as the focus of applications has moved from the traditional information systems domain to the WWW. In this paper, the requirements of development methodologies in the Web era are examined. An Internet commerce development methodology is proposed which addresses many of these issues (ICDM). The methodology is compared with other Web development approaches and the issues related to evaluating methodologies are discussed. Finally, suggestions are made for future research.

\section{DEVELOPING WEB APPLICATIONS}

The Internet and the World-Wide-Web have had a profound impact on the business world. The changing business landscape has also impacted on the requirements of systems development approaches (Howcroft \& 
Carroll, 2000; Davies, 2000). The list below provides a representative summary of the issues related to ebusiness applications development.

- Business Focus

E-business should be driven by business strategy not the implementation of technology (Treese \& Stewart, 1998);

- External focus (Customer Focus)

E-Business applications have a customer focus which impact on the gathering of requirements and development team composition (Rockwell, 1998; Treese and Stewart, 1998);

- Speed of change

The rapidly changing business environment influences the need for short development cycles and the need for evolutionary development approaches (May, 2000).

It would appear that many of the issues being discussed in Electronic Commerce (EC) development are not particularly new. Taking a business perspective, the role of methodologies, evolutionary development approaches, speed of development and effective project management have all been topics of concern for many years (Avison \& Fitzgerald, 1995; Gilb, 1988; Boehm, 1988). Rather than viewing Web commerce as a radically new development paradigm it can be viewed as an evolutionary stage in the discipline of information systems. However, the implications of much of what is being written on e-business applications development suggest that more traditional IS Development Methodologies are no longer suitable as a development framework (Avison \& Fitzgerald, 1995).

\section{KEY FEATURES OF ICDM}

In this section, the main features of the Internet Commerce Development Methodology (ICDM) are outlined. ICDM attempts to address the issues related to emphasising a business focus, external focus and speed of change. The description of the Methodology is guided by the framework for analysing methodologies provided by Avison and Fitzgerald (1995).

\section{A) Philosophy}

ICDM views e-business developments as organisational initiatives and as such takes into account the need to address strategic, business, managerial, and organisational culture issues as well as the technical details of design and implementation. In this respect, the Methodology takes an holistic subjectivist perspective arguing that e-commerce applications will not be effective unless the organisational management and culture is conducive to change.

Defining an organisation's e-business strategy involves dealing with a range of information sources and opinions. A question such as "how can the organisation effectively employ e-commerce? is inherently subjective in nature and any definition of effective will be socially constructed to a large extent. ICDM relies on competitive analysis to help shape the e-business direction (SWOT Analysis).

ICDM emphasises the organisational environment in that it considers the merging of functional boundaries and the political and cultural nuances of working in teams. The methods used for the development of business strategy and for the definition of requirements (brainstorming and groups requirements sessions) are intensely social in nature. This factor recognises strategy is a socially constituted process and is not static. Internet commerce should be a continually evolving feature of the organisation and as such any methodology to support it should be interwoven with a dynamic learning environment.

As a consequence of the changes in the business environment, organisations have had to change in form (Limerick, Cunnington, \& Crowther, 1993). This has influenced organisational structure and management approaches. Flatter organisational structures have replaced many deep hierarchical organisational structures. Team based structures which frequently change according to the required skills-mix are an alternative to 
rigid departmental structures based upon functional lines. Teams are usually faster to adapt to a service and customer focus than large departments. The Internet Commerce Development Methodology (ICDM) can only be successful if its context is appropriate and effective. An organisational methodology, such as ICDM, is inextricably linked with the organisational structures, management strategies and approaches.

\section{B) Scope}

ICDM is a business analysis methodology as well as a systems development methodology. Many traditional information systems methodologies only cover the more technical aspects of systems development and do not start with any form of business analysis. Internet commerce is first and foremost a business direction and hence requires a thorough analysis of its place in the overall business strategy.

The Internet Commerce Development Methodology (ICDM) takes into account the wider trends in the business world and society in its strategy development phase with the SWOT analysis. The changing profile of the consumer is important and user or customer involvement is factored in at various points in the methodology. It is no longer sufficient for a methodology to be inwardly focused, it must provide a mechanism for scanning the wider business environment. With the trend towards globalisation of economic markets an organisation must be continually looking for opportunities and learning on a global level (Clarke \& Clegg, 1998).

ICDM recommends a management structure for the evolution of Internet commerce in an organisation. Taking a project of electronic commerce is dangerous as the systems are continually changing. An evolutionary perspective is more apposite. The first tier of the three-tier management and development structure has the responsibility of overseeing the evolving form of e-business.

\section{C) Techniques and Tools}

ICDM has a number of component phases to guide the development of strategy and the Web site. Issues related to Web page design, database connections, security issues, and implementation tools and methods are all covered.

\section{D) Framework}

ICDM provides a framework for developing Internet commerce. It is not a prescriptive methodology with a large number of steps to be completed. It is a loose fitting framework for developing strategies and for the evolutionary development of Web based systems. As a result it is applicable to a wide range of situations where organisations are looking to gain from investing in Internet commerce. The approach acknowledges that organisational development via Internet commerce is sufficiently complex and varied to warrant the use of guidelines rather than detailed tasks that lack general applicability. This allows the company to adapt the methodology to the specialised conditions of the organisation.

\section{OVERVIEW OF ICDM}

This paper proposes the Internet Commerce Development Methodology (ICDM) as a framework for the development of Internet Commerce in an organisational context (figure 1) (Standing, 2000). ICDM provides both a management strategy and a development strategy which are driven by the needs of the business. Studies have shown that methodologies have been chosen, frequently by the IS Department, which do not reflect the needs of the business (Sauer \& Lau, 1997). Hence, ICDM gives particular attention to providing a business focus.

ICDM has the following components and features which are described in the remainder of this section.

- Web Management structure

- Strategy and business analysis development phase

SWOT Analysis

Level of Change - Business Process Re-engineering or Value Chain Analysis

- User Involvment

- Meta-development strategy 
- Analysis phase

Requirements techniques

Functional requirements framework

- Physical architecture framework

- Design phase

- Component implementation and evolution

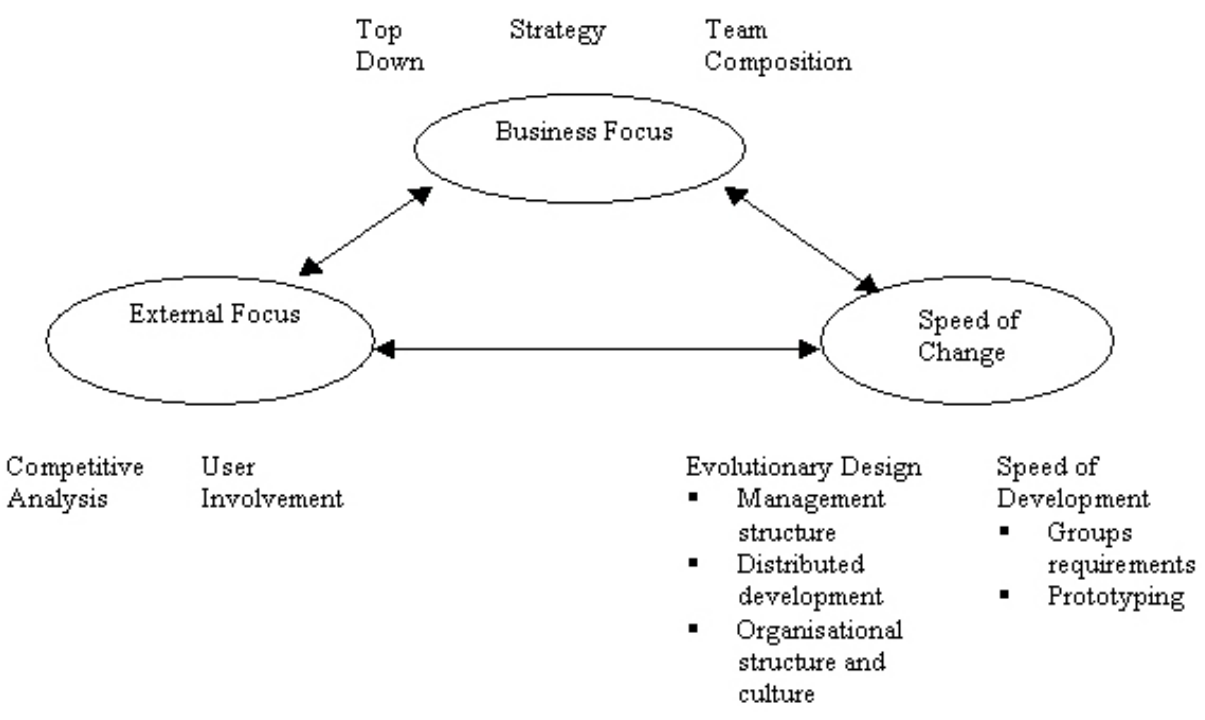

Figure 1: Key requirements and techniques of ICDM

\subsection{Web Management Strategy}

ICDM recommends the management and development of e-business systems on three levels (figure 2). The overall management and development of the entire Web strategy can be seen as an on-going task as well as the development of the functional components of a Web application. The first tier is a meta-development and management perspective that provides a framework for development. The second tier concerns the development of the components of the Web site. At both levels the work must be seen as being evolutionary in nature, to cope with the inevitable changes that will have to be made. The third tier in the management and development structure is concerned with developing and implementing the system and so includes technical development teams, analysts, content specialists and Web development consultants.

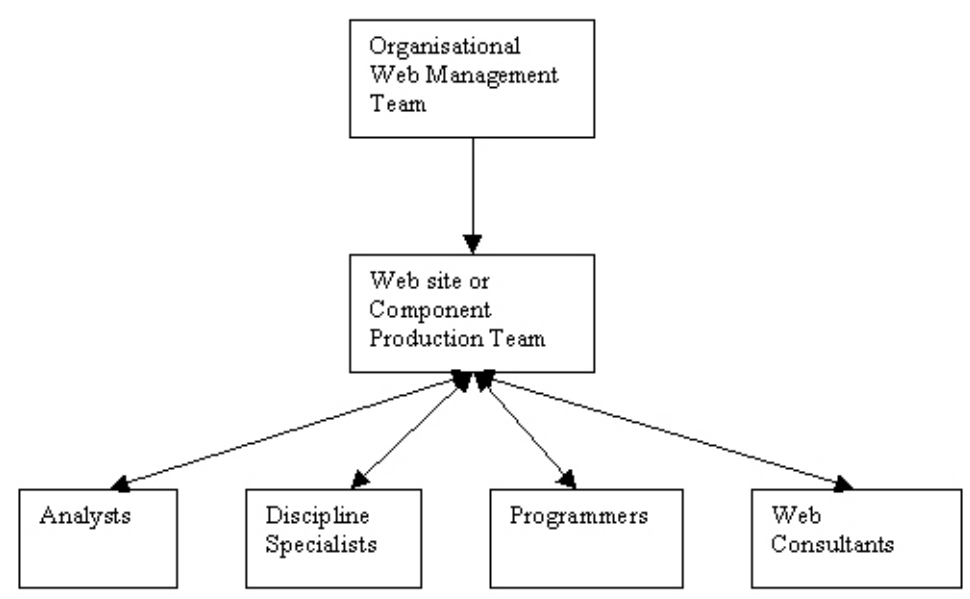

Figure 2: Web management and development structure 


\subsection{Strategy Development Phase of ICDM}

The use of the Internet for business purposes can take many forms. The Internet can be used strategically as a transformation agent to radically change the nature of the business. It can also be employed to improve processes or parts of processes over time and incrementally add-value to the business. The Internet Commerce Development Methodology (ICDM), proposed in this paper, provides a strategic planning approach that considers which option is most appropriate for a given situation (figure 3). ICDM draws upon Business Process Re-engineering (BPR) and Value Chain Analysis for its core strategic planning tools.

To decide upon a strategy for a business, business unit or functional area, managers need to assess an organisation's competitive situation. This involves assessing the organisation and its environment. The process is known as competitive analysis. SWOT analysis is one method of competitive analysis (Thompson \& Strickland, 1995). The competitive situation for the company is assessed by examining its strengths (S), weaknesses (W), environmental opportunities $(\mathrm{O})$ and threats $(\mathrm{T})$. The competitive analysis will yield different results for each business examined (figure 3).

The strengths examined in the SWOT analysis are the strengths of the business. The internal strengths are features of the organisation such as streamlined administrative systems, or technologically adept staff. The internal weaknesses of the organisation can be detailed in much the same way. The wider environment can be scanned for economic, technological and social trends that can be exploited. For example, new government legislation may create an opportunity for some organisations.

Besides performing a competitive analysis, organisations should assess the threat of disintermediation. Due to the ease with which suppliers of products and services can market and sell directly to consumers those companies that act as intermediaries in the distribution chain risk being by-passed. This would clearly have disastrous consequences for the intermediaries and is termed disintermediation. The businesses that are most at risk of disintermediation are those that do not significantly add value to the products and services they are distributing.

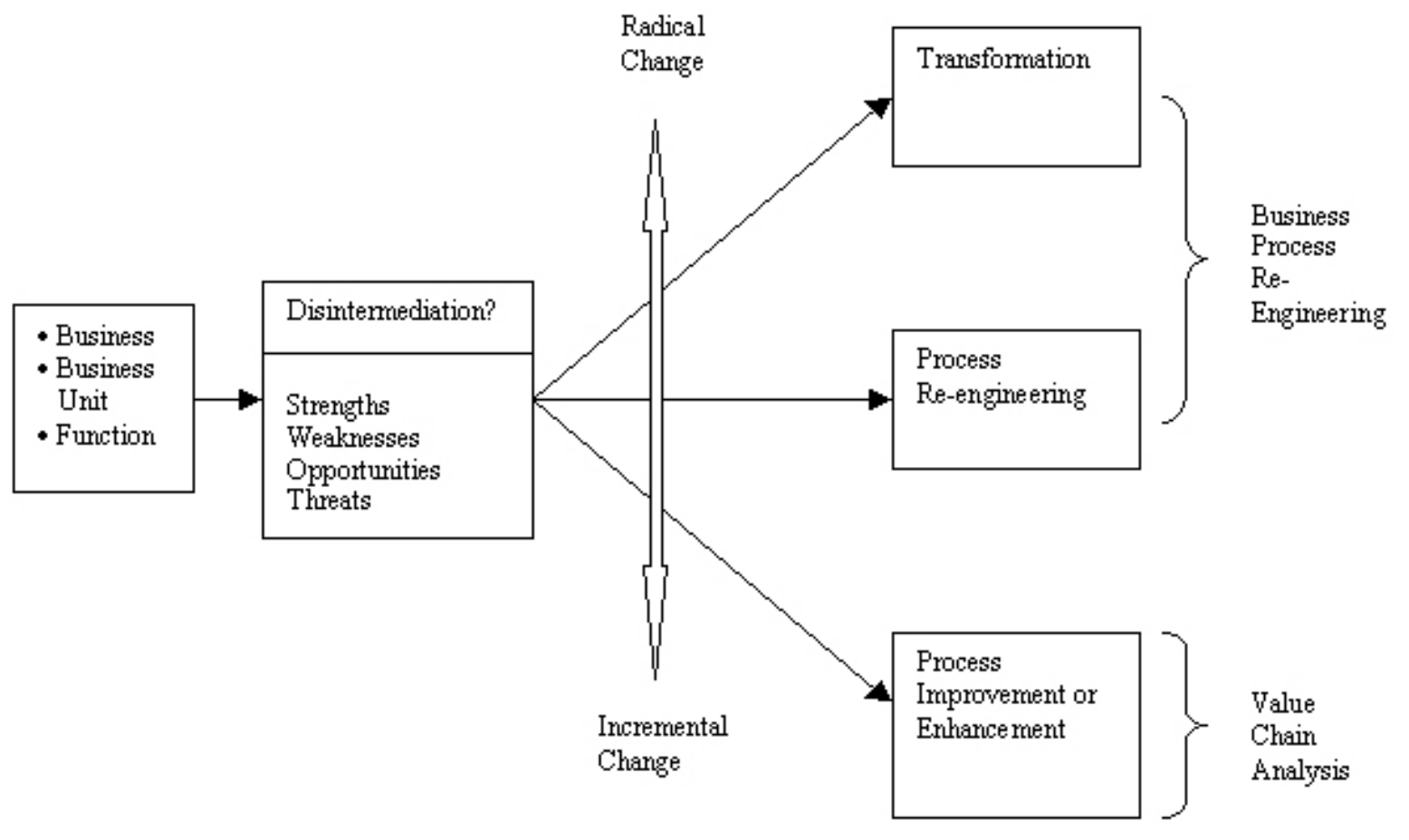

Figure 3: ICDM Strategic Planning Phase

The scale and scope of the changes should fall in to one of three categories: process change, process-reengineering, or transformation. Process change is related to the enhancement or modification of an organisational process with the aid of the Internet. Value chain analysis can be used to identify where value 
can be added for the customer. Process re-engineering is the complete redesign of a process with the aid of the Internet. Transformation is the radical change of a business leveraging Internet technology.

\subsection{Meta-Development Strategy}

There are a number of strategies that can be employed by a company when managing the development of a Web site. The options depend upon the amount of regulation or control that is desired, both for content and design.

1) Plan the entire site and regulate its distributed development in consultation with business units.

2) Plan the core of the Web site and allow business units the autonomy to develop their own neighbourhoods.

ICDM proposes that the decision on which option to adopt should be taken by the Web management team.

\subsection{User Involvement}

Customers or suppliers (users) of the systems should be involved at various stages of the e-business operations and be included in periodic reviews. Customer input is essential at the strategy development and business analysis stages and may involve the use of market research teams to obtain information on what customers require and barriers to using the Web. More detailed requirements can be obtained in Group Requirements Sessions (GRS), telephone interviews or questionnaires. Customers can be involved in evaluating design issues through the use of prototype Web systems and they should be included in testing and evaluation of the Web site. Feedback can be obtained from users once the Web site is 'live'. As the ebusines strategy is likely to evolve through time focus groups can be used to provide input through reviewing the current system and making recommendations.

\subsection{Site and Component Development}

Functional or divisional components of the Internet system can be approached as discrete projects. The implications of the integration with other components of the Web application still need to be considered. A functional component could be a component that provides customers with the option to interrogate a database of products, or to obtain details about customers for marketing purposes. Even so, a multidisciplinary team is still required because any component of a Web site is still concerned with implementing business strategy not just technology.

\subsection{Requirements Analysis Techniques}

There are a number of information gathering techniques that are especially relevant to the process of defining the requirements of Web applications. These methods are useful for projects where some degree of innovation can substantially improve the success of the system by providing a competitive edge for the organisation.

Using group communication techniques can speed up the definition of the logical requirements for a Web application. The two group communication techniques used in the Internet Commerce Development Methodology (ICDM) are brainstorming and the Group Requirements Sessions (GRS). The first is used to define alternative ways of using Internet commerce in the business and the second is about obtaining the detailed requirements within a relatively fast time frame with involvemnet from customers, suppliers and internal staff.

Prototypes can be developed to help in defining the requirements. In particular, the detailed information requirements of transaction and marketing systems can be trialled with customers. The prototypes, however, will be used to a greater extent in the design phase of development. 


\subsection{Functional Requirements Framework}

Web applications fall into a number of categories. These functional applications need the detailed definition of their requirements. It is beyond the scope of this paper to explain the detailed requirements of these systems but the analysts need to use the analysis techniques described earlier to make sure that the business objectives are being met.

\subsection{Physical Architecture Framework}

The techniques used for defining the requirements for an Internet project depend on the type of system and its functionality. There are three fundamental types of Web systems: document publishing systems, basic interactive systems, and complex transaction systems. It is not always the case that Web projects intending to transform the organisation require complex transaction systems. Useful information, clearly and effectively presented, with some simple database interactivity has the potential to make a major impact on a business.

\subsection{Design Phase}

The design phase, although not discussed in detail in this paper, involves designing the network infrastructure, developing the Web site and developing security controls. The Web site design should consider:

- Desired Image

- Usability

- Promotion

- Evaluation with customers

\subsection{Implementation and Evolution Phases}

The implementation of the Web site relates to the meta-development strategies discussed earlier. It is unlikely, unless the Web site is small, that all the site will be designed and implemented in one project cycle. Web applications evolve and so rarely have a well defined project completion. However, there are cases where components of the Web site, such as transaction modules can be implemented and remain reasonably stable. The continual evolution of the site should also be managed by the organisation's Web management team. This team should be made up of senior people from each functional unit of the organisation. It is their task to oversee the implementation of the Web strategy and changes in strategic direction. They should also set policy on who can add to the Web site and content and design guidelines.

\section{A COMPARISON OF ICDM WITH OTHER WEB DEVELOPMENT METHODOLOGIES}

To highlight the contribution of ICDM it is now compared with a number of other Web applications development methodologies (table 1). The framework used for the comparision uses philosophy, scope, key techniques and tools, the focus of the methodology, internal/external emphasis and the systems development perspective.

The three other methods concentrate on the task of Web site development and the technical architecture. ICDM is the only method that emphasises strategy and business analysis. Indeed, the focus is equally on developing a management structure and conducive organisational culture as well as Web applications development. The other methodologies do not directly address the importance of evolutionary development issues taking more of a traditional project approach to development. It is important that methodologies for Web development include ways of obtaining customer (user) and outside input in the requirements, design and evaluation stages. Only ICDM addresses this issue. 
The Requirements of Methodologies for Developing Web Applications

\begin{tabular}{|l|l|l|l|l|}
\hline & ICDM (Standing, 2000) & $\begin{array}{l}\text { Howcroft \& Carroll, } \\
\mathbf{2 0 0 0}\end{array}$ & $\begin{array}{l}\text { Fournier, R. } \\
\mathbf{1 9 9 8}\end{array}$ & $\begin{array}{l}\text { Web Application } \\
\text { Extension } \\
\text { (Conallen, 2000) }\end{array}$ \\
\hline Philosophy & Subjectivist & Objectivist/Structured & Objectivist & Objectivist \\
\hline Scope & $\begin{array}{l}\text { Business analysis, } \\
\text { organisational change, } \\
\text { analysis, design, } \\
\text { implementation. }\end{array}$ & $\begin{array}{l}\text { Analysis to } \\
\text { implementation }\end{array}$ & $\begin{array}{l}\text { Analysis to } \\
\text { implementation }\end{array}$ & $\begin{array}{l}\text { Analysis to } \\
\text { implementation }\end{array}$ \\
\hline $\begin{array}{l}\text { Key Techniques } \\
\text { and Tools }\end{array}$ & $\begin{array}{l}\text { Management structure } \\
\text { Team composition } \\
\text { SWOT analysis and BPR } \\
\text { Group requirements definition } \\
\text { User involvement framework } \\
\text { Design guidelines }\end{array}$ & $\begin{array}{l}\text { Objectives analysis } \\
\text { Web site design }\end{array}$ & $\begin{array}{l}\text { Technical } \\
\text { architecture } \\
\text { design } \\
\text { Joint Facilitated } \\
\text { Sessions }\end{array}$ & $\begin{array}{l}\text { Object oriented } \\
\text { analysis and design }\end{array}$ \\
\hline $\begin{array}{l}\text { Focus of } \\
\text { methodology }\end{array}$ & $\begin{array}{l}\text { Organisational infrastructure/ } \\
\text { Web application }\end{array}$ & Web Application & $\begin{array}{l}\text { Information } \\
\text { Architecture }\end{array}$ & $\begin{array}{l}\text { Software } \\
\text { Application }\end{array}$ \\
\hline $\begin{array}{l}\text { Systems } \\
\text { Development } \\
\text { View }\end{array}$ & Evolutionary & Project view & Project view & $\begin{array}{l}\text { Project/evolutionary } \\
\text { view }\end{array}$ \\
\hline $\begin{array}{l}\text { External/Internal } \\
\text { Emphasis }\end{array}$ & External & Internal & Internal & Internal \\
\hline
\end{tabular}

Table 1: A comparison of Web development methodologies

\section{EVALUATING METHODOLOGIES}

A development methodology can be evaluated in a variety of ways. It could be evaluated according to a framework of requirements or rationale to determine if these are met with the approach. The benefit of this is that it can be carried out by the system developers and so is relatively inexpensive and fast to conduct. Of course, the weakness is that all problems are unlikely to be identified.

Focus groups are another method of evaluating methodologies. ICDM has been evaluated with several focus groups. Each group was presented with extensive material documenting ICDM. A seminar lasting three hours was also conducted, at the end of which the participants discussed the methodology. The participants were then asked to list the strengths and weaknesses of the methodology for developing Internet commerce systems. This approach has the advantage of getting input from a range of people including practioners and experts in the field. Again the limitation is that all issues and problems may not be identified until the methodology is used in practice.

The methodology can be evaluated by adopting it as the development methodology on a project as a form of action research.. This is an ideal approach to evaluating a methodology. The difficulty is getting a company to trial the use of the methodology when it has not been 'tested' in practice.

\section{LIMITATIONS OF THE METHODOLOGY}

A number of limitations or weaknesses were identified by the focus groups in relation to ICDM and these are now discussed. Whilst the consideration of developing an effective organisational culture was listed as a strength of the methodology it was mentioned that more details need to be included on how to facilitate this. Creating an innovative organisational culture is not a simple task and of course every company is at a different starting point. Perhaps unrealistic expectations are made on development methodologies but it does highlight the recognition given by practitioners to the issue and the difficulties they face. 
A recurring issue in relation to systems development methodologies is providing sufficiently flexible guidelines and providing support for industry specific factors. Many industry sectors, for example, employ ecommerce primarily for business-to-business activities and although the methodology provides some discussion of the development issues in this area it is rather limited.

The travel agents commented on the time involved in working through such a methodology. As small businesses much of the development work would be out-sourced. Although ICDM provides guidelines for selecting Web consultants it still exposes the developer to the full range of tasks and phases of Web development.

\section{CONCLUSIONS}

Although ICDM has been recognised as having some useful and effective features for Web applications development there are still issues which need to be addressed. Practitioners, it would seem, desire approaches that are tailor made for their industry. This is difficult to fully consider in a methodology other than through multiple variations of the methods and techniques. However, there may be a clear divide for methodologies which focus on business-to-business and business-to-consumer applications development. In addition, the methodology and organisational environment boundary is blurring. Practitioners require detailed guidelines on how to create a conducive organisational culture that will stimulate innovative thinking and wide-spread adoption of e-commerce initiatives. Both of these issues are difficult for methodology designers to adequately take on board but will nonetheless be essential if methodologies are to retain their sense of relevancy.

\section{REFERENCES}

Avison, D. E. \& Fitzgerald, G. (1999). Information Systems Development. In Galliers, R. \& Currie, W. (Eds.) Rethinking Management Information Systems. Oxford University Press.

Avison, D. E. \& Fitzgerald, G. (1995). Information Systems Development: Methodologies, Techniques and Tools. McGraw-Hill.

Avison, D. E. \& Wood-Harper, A. T. (1990). Multiview: An Exploration in Information Systems Development. Blackwell Scientific Publications, Oxford.

Boehm, B. (1988). The Spiral Model of Software Development and Enhancement. Computer, Vol. 21, No. 5, pp. 61-72.

Conallen, J. (2000). Building Web Applications with UML. Addison Wesley.

Clarke, T. \& Clegg, S. (1998). Changing Paradigms: The transformation of management knowledge for the $21^{\text {st }}$ Century. Harper Collins.

Davies, P. (2000). Survival of the Fittest. The Computer Bulletin, Series 5, Vol. 2, part 5, p28-29.

Fournier, R. (1998). A Methodology for Client Server and Web Application Development. Yourdon Press.

Gilb, T. (1988). Principles of Software Engineering Management. Addison-Wesley.

Gordon, S. R. \& Gordon, J. R. (1996). Information Systems: A Management Approach. Dryden.

Howcroft, D \& Carroll, J. (2000). A Proposed Methodology for Web Development. Proceedings of the European Conference on Information Systems, Vienna, pp. 290-297.

Limerick, D., Cunnington, B. \& Crowther, F. (1993). Managing the New Organisation. B \& BP.

May, P. (2000). The Business of Ecommerce. Cambridge Press.

Rockwell, B. (1998). Using The Internet To Compete in a Global Marketplace. Wiley \& Sons. 
Sauer, C. \& Lau, C. (1997). Trying to adopt systems development methodologies - a case-based exploration of business users' interests. Information Systems Journal, 7(4), p.255-275.

Standing, C., Vasudavan, T., \& Borbely, S. (1999). A Study of Web Technology Diffusion In Travel Agencies. Proceedings of the Hawaii International Conference on System Sciences.

Standing, C. (2000). Internet Commerce Development. Artech House Publishers, Boston.

Thompson, A.A. \& Strickland, A. J. III. (1995). Strategic Management: Concepts and Cases, $8^{\text {th }}$ Edition, Homewood: Richard D Irwin, Inc.

Treese, G. W. \& Stewart, L. C. (1998). Designing Systems For Internet Commerce. Addison-Wesley. 